\title{
Comparison of speech articulation and intelligibility in palatally contoured dentures using a novel rugae duplication technique: A clinical study
}

\author{
Priya Vaswani $^{1 *}$, Pronob Sanyal ${ }^{2}$, Ankur Prajapati ${ }^{1}$ \\ ${ }^{1}$ Post Graduate Student of Prosthodontics, Crown and Bridge, School of Dental Sciences, KIMS-Deemed University \\ ${ }_{2}^{2}$ Professor (MDS) \& HOD (Department of Prosthodontics, Crown and Bridge) \\ *Corresponding author E-mail: vaswani.priya577@gmail.com
}

\begin{abstract}
Background: Speech is essential to human activity. Loss of teeth is usually accompanied by eventual loss of oral morphology responsible for articulation. Palatal rugae contour has an important role in phonetics by production of linguo-palatal sounds that involves the contact between tongue and palate.

Objectives: To analyze the improvement in linguo-palatal sounds by duplicating the existing rugae in maxillary complete denture prosthesis using two different impression materials in shallow, medium \& deep palatal vault configuration.

Methods: Twenty four completely edentulous patients were selected that were categorized eight in each category of shallow, medium \& deep palatal vaults. Existing rugae were duplicated using mucocompressive and mucostatic impression material, wax pattern obtained through these impressions were incorporated in maxillary dental prosthesis. Later speech was recorded and analyzed by a speech pathologist with an aid of speech rating scale over a period of eight weeks.

Results: Mann-Whitney U test and Wilcoxon matched pair test showed statistical significance in speech improvement $(\mathrm{p}<0.05)$ when mucostatic impression derived rugae pattern was incorporated in upper arch prosthesis.

Conclusion: Using the presently described rugae duplication technique, speech improvement is rapid in case when mucostatic impression material was used.
\end{abstract}

Keywords: Linguopalatal Sounds; Phonetics; Rugae Duplication; Rugae Wax Pattern; Speech Rating Scale

\section{Introduction}

Speech is an integral part of human communication, which makes the human species superior to other life forms. Although every prosthodontist aims at providing excellent complete denture prosthesis in terms of esthetics, functional efficiency and comfort, a thorough evaluation of phonetics is too often neglected with greater emphasis placed on other three components. Loss of teeth is usually accompanied by eventual loss of oral morphology responsible for the articulation of certain speech sounds. Some patients do not experience any speech problems because it appears that tongue makes compensatory adjustments for the absence of teeth. Allen had stated that a patient fitted with complete dentures generally adjusts his speech pattern to the new appliance and thus improves (Allen LR 1958) .Martone reported that older patients when fitted with complete dentures show a resistance to speech improvement (Martin AL 1963) .Speech consists of respiration, phonation, resonation, articulation, neural Integration, and audition, of these components articulation is mostly affected by construction of complete denture. Articulation by definition is resonated sound formed into meaningful speech by the movements of the mandible, lips, tongue, soft palate, hard palate, alveolar ridge and teeth. The tongue, lips, and soft palate are dynamic structures that control and direct the air movement. Rapid and precise movements of tongue and lips occurred across the static structures.
Their approximation to the teeth, the hard palate, and the alveolar processes creates valves for the production of specific sounds of speech like lingual-dental, lingual-alveolar, and palatal consonants. Tanaka reported that a reverse curve exists in the sagittal and frontal sections of the palate in dentate patients (Fig.1) (Tanaka H 1973). This this convexity is important for pronunciation of the sibilant sounds such as $/ \mathrm{s} /$ and $/ \mathrm{sh} /$. If the anterior palatal area is overcontoured such that air stream is excessively impeded, an /s/ sound may be heard as central or frontal lisp (Fig.1.a).However, if this area is under contoured, resulting in an insufficient impeding of the air stream, an /s/ sound may be perceived as whistle (Fig.1.a). Optimal phonetics can best be achieved by obtaining a proper occlusal vertical dimension (OVD) and occlusal plane, correctly positioning the anterior and posterior teeth to suit best the functional and esthetic requirements, as well as well as adequately contouring the palatal surface. Because the lack of texture on the palatal portion of a complete denture can impede proper articulation, one solution is to add palatal rugae. The purpose of this article is to present a newly developed technique of adding patient's existing palatal rugae using two different impression material and to evaluate the speech enhancement, particularly the linguo-palatal sounds over a period of eight weeks. 


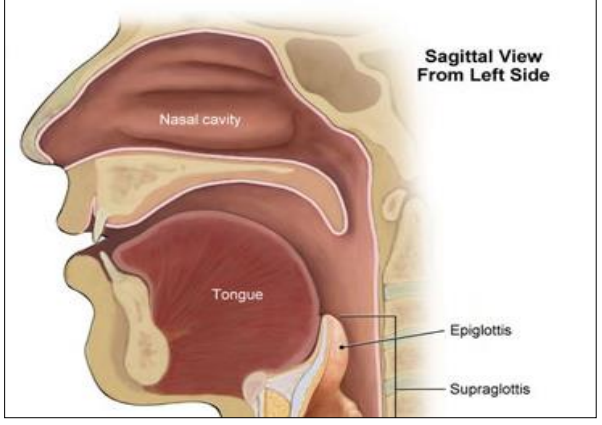

Fig .1: Reverse Curve in Sagittal Section

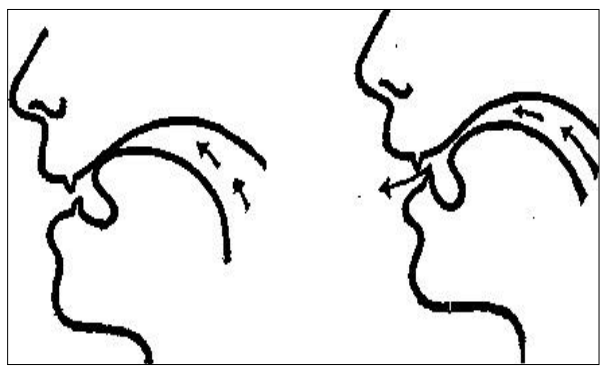

Fig. 1: A) Undercontoring and Overcontouring of Palate

\section{Objectives}

1) To compare and analyze the improvement in speech sounds /s/ and /sh/ using palatally contoured dentures when rugae is duplicated using two different impression materials in varying palatal depth configuration.

2) To evaluate the most suitable impression material for a given palatal vault depth

\section{Material and methods}

Forty two completely edentulous patients were selected from outpatient Department of Prosthodontics, Crown and Bridge, School of Dental Sciences, KIMS University, Karad with a chief complaint of difficulty in mastication due to the absence of teeth twelve of them even reported of unclear speech. Only twenty four out of Forty two were selected as they best suited the Inclusion criteria and exclusion criteria for the study as per the guidelines in Table 1. After obtaining a thorough case history and informed consent, diagnostic impressions were made(Impression compound-Y dents, MDM Corp) and poured in dental plaster, later primary casts were analyzed for palatal depth configuration (Fig.2) (Kazanjeet al. 2008).Patients were categorized of having shallow, medium, and deep palates such that the distance from the deepest point in the midline of upper diagnostic cast upto the crest of the ridge if measured between $15.5-20 \mathrm{~mm}$ was considered as deep palate, those readings between $10.5-15 \mathrm{~mm}$ as medium and those reading measured that ranged between $5.5-10 \mathrm{~mm}$ as shallow. In this manner, a total of eight patients were present in each category of having shallow, medium, and deep palatal vault (Kazanjeet al. 2008).

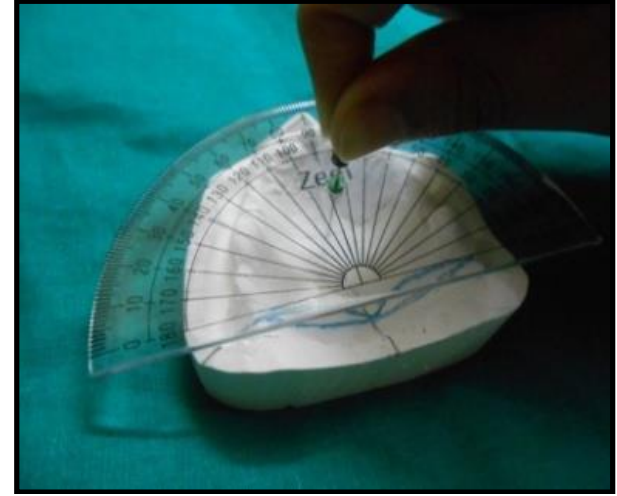

Fig. 2: Palatal Depth Measurement

Table 1: Inclusion and Exclusion Criteria

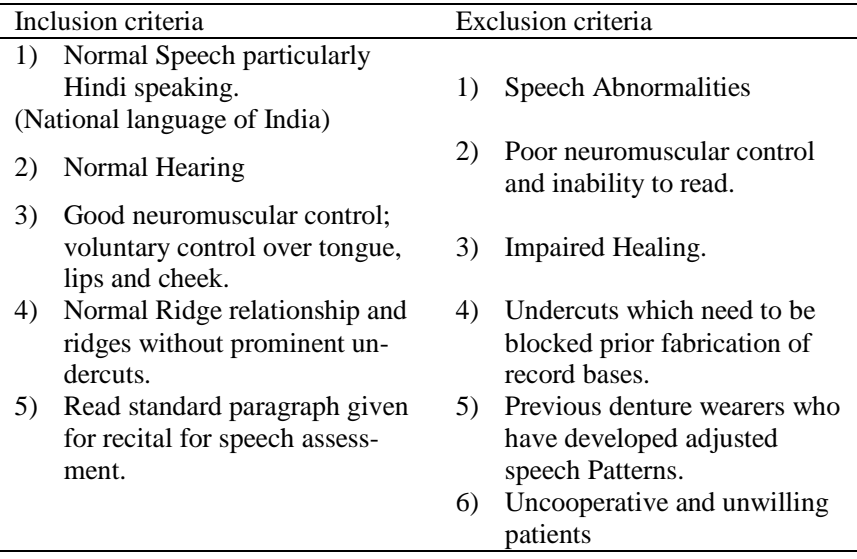

Final impressions of maxillary and mandibular arch for each patient were made using green stick (Low fusing compound; DPI Pinnacle, Mumbai,India) for marginal trimming followed by wash impression using Zinc oxide Eugenol impression paste(Neogenate-Septodent).

Master cast thus obtained were duplicated using Agar-Agar (Castogel Bego ,Germany) (Fig.3)as a medium for each palatal vault configuration such that two maxillary cast were obtained for each patient. Record bases were fabricated using autopolymerising resin on both the casts having a uniform thickness of $2 \mathrm{~mm}$, this was followed by facebow transfer and mounting of original master cast in centric relation, two tooth moulds of same size ,shape and shade were selected.

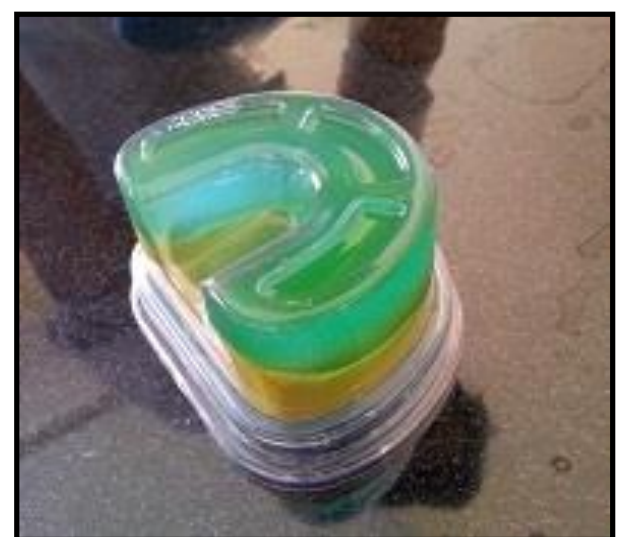

Fig. 3: Duplication of Master Cast (Maxillary) Using Agar agar.

During the same appointment two maxillary arch impressions of each using Mucostatic (Alginate-Marieflex,Septodent) and Mucocompressive (Impression compound-Ydents,MDM Corp) impression materials were made. Type II Inlay wax (BEGO) was added to these impressions to obtain a wax pattern duplicating the existing rugae for all the patients (Fig.4). 


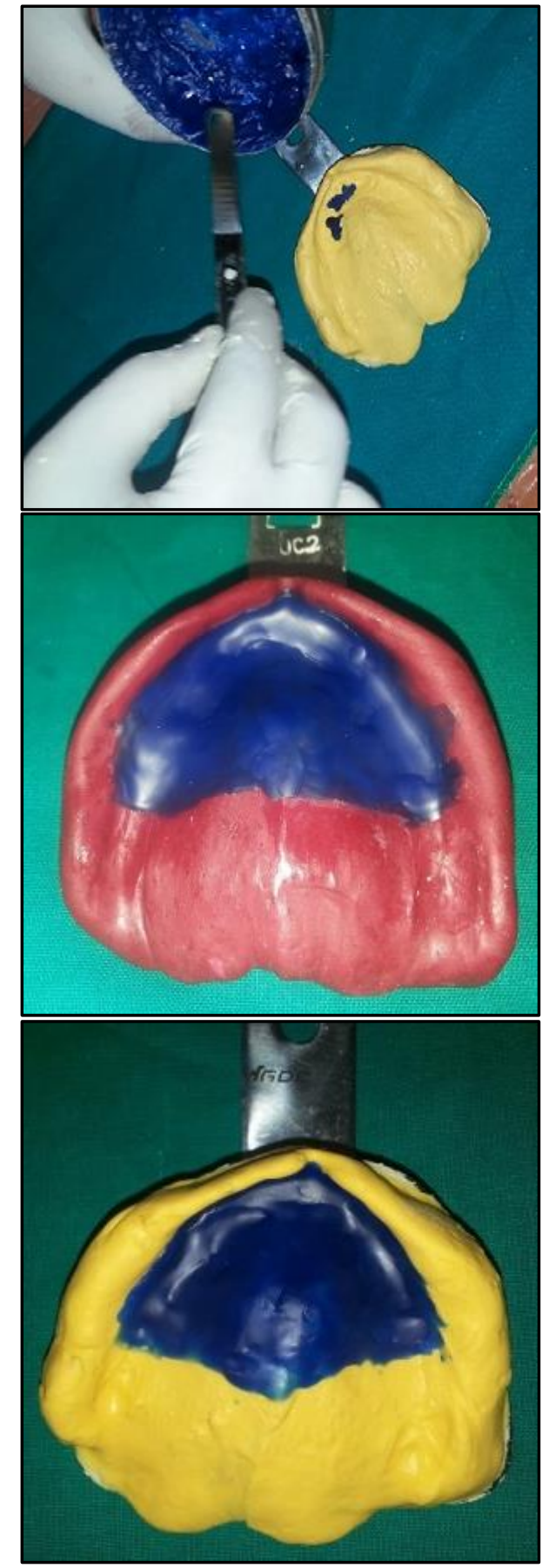

Fig. 4: Duplication of Existing Rugae in Wax Pattern Using Inlay Wax (Bego).

In case of mucocompressive impression using medium fusing compound prior to addition of inlay wax for wax pattern fabrication, the impression was chilled at temperature of 4 degree Celsius in order to prevent thermal shock distortion of the impression during addition of softened inlay wax. On the previously mounted vertical dimension of occlusion, teeth arrangement was carried out on the record base fabricated on original master cast, after complete arrangement, record bases were interchanged such that those bases fabricated on duplicated cast were placed on the original mounted cast, and teeth from second mold were arranged to achieve desired occlusion. After arrangement of upper anterior teeth, a flame shaped tungsten carbide bur or a round bur was used to reduce the thickness of record bases fabricated on both the final cast in the anterior region so that the thickness obtained was 0.5 mm.(Fig.5)Wax pattern of rugae was retrieved; incisive papillae, labial frenum and midline were used as the guide for proper orientation and adaptation of the wax pattern on the trimmed record bases followed by posterior teeth arrangement(Fig.6\&6.a). Try-in of both the upper record bases was carried out for all twenty four patients. During processing, labelling was done such that S1,M1, D1 represented shallow ,medium, and deep palatal vaults, wherein the rugae was duplicated with the wax pattern obtained from $\mathrm{Mu}$ cocompressive impression.Similarly, labelling of S2, M2, D2 represented rugae was duplicated with the wax pattern obtained from Mucostatic impression. A total of two upper denturesand one lower denture was fabricated for all the twenty four patients of different palatal vaults. Analysis of speech began weeks after denture insertion for all the twenty four patients whereby they were instructed to wear the given set of two upper dentures alternatively every week for the period of eight weeks. Speech was analysed in a specialized audio recording room with the help of a graduate speech pathologist by inserting both Maxillary and Mandibular dentures. The two set of upper dentures made having rugae incorporated from respective impressions were inserted each time when speech was analysed. Each patient was made to read a test paragraph complementary to a speech rating scale (Fig.7) devised by Speech-language pathology Department AYJNIHH,1984 containing and stressing on words 't', 'd', 'n', 'l' ,'s','sh'.

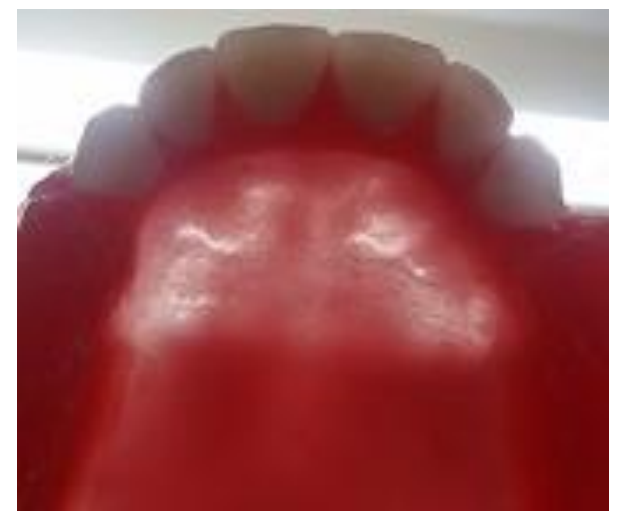

Fig. 5: Trimmed Record Base.

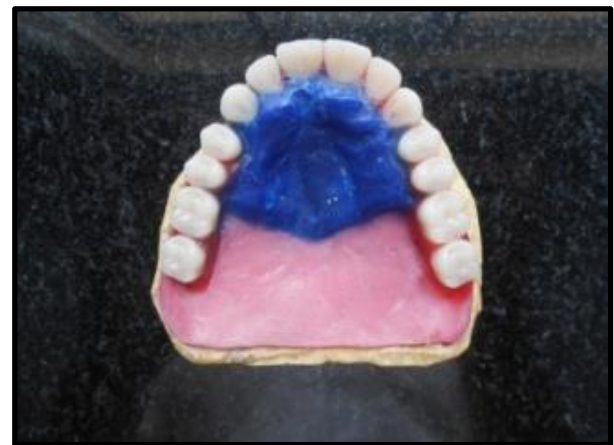

Fig. 6: Wax Pattern from Mucostatic Impression.

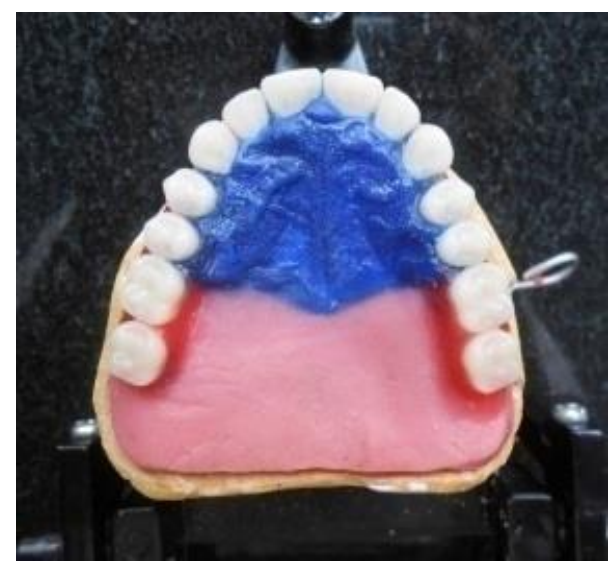

Fig. 6: A) Wax Pattern from Mucostatic Impression 
The Speech Rating Scale used (Developed by Speech language Pathology Dept, AYJNIHH, 1984)

0-Normal.

1-Can understand without difficulty. However feels speech is not normal.

2-Can understand with little efforts

3-Can understand with concentration and effort, especially by a sympathetic listener.

4-Can understand with difficulty and concentration by family, but not by others

5- Can understand with effort if context is known.

6-Cannot understand at all, even when context is known.

Fig. 7: Speech Rating Scale.

The testing procedure was double blinded as the assessors and the patients were not told about the set of upper denture being used, and the scores were given by the pathologist after analysing the recorded speech for all the participants with reference to the scale having a maximum score of 6 indicating that speech could not be understood even when the context in paragraph was known.

\section{Results/data}

The speech analysed for twenty four participants had been following scores tabulated during intervals after $1^{\text {st }}$ week, after $2^{\text {nd }}$ week and subsequently after 8th-week post denture insertion is as follows.

\begin{tabular}{|c|c|c|c|c|c|c|}
\hline \multirow[t]{3}{*}{ No of Weeks } & \multicolumn{2}{|c|}{$\begin{array}{l}\text { Shallow palatal } \\
\text { vault }\end{array}$} & \multicolumn{2}{|c|}{$\begin{array}{l}\text { Medium palatal } \\
\text { vault }\end{array}$} & \multicolumn{2}{|c|}{$\begin{array}{l}\text { Deep palatal } \\
\text { vault }\end{array}$} \\
\hline & $\mathrm{Mc}$ & Ms & $\mathrm{Mc}$ & Ms & $\mathrm{Mc}$ & Ms \\
\hline & $\mathrm{S} 1$ & $\mathrm{~S} 2$ & M1 & M2 & D1 & D2 \\
\hline & 4 & 4 & 4 & 4 & 4 & 4 \\
\hline WEEK 1 & 5 & 3 & 5 & 4 & 4 & 5 \\
\hline Post denture & 4 & 3 & 4 & 5 & 4 & 4 \\
\hline \multirow[t]{2}{*}{ insertion } & 5 & 4 & 5 & 5 & 5 & 3 \\
\hline & 3 & 3 & 4 & 3 & 4 & 4 \\
\hline (Eight patients & 4 & 3 & 5 & 4 & 5 & 3 \\
\hline \multirow[t]{3}{*}{ each) } & 4 & 4 & 4 & 5 & 4 & 4 \\
\hline & 4 & 3 & 4 & 4 & 5 & 4 \\
\hline & 3 & 2 & 3 & 4 & 4 & 3 \\
\hline WEEK2 & 3 & 3 & 4 & 3 & 3 & 2 \\
\hline Post denture & 3 & 2 & 3 & 3 & 3 & 2 \\
\hline \multirow[t]{2}{*}{ insertion } & 4 & 2 & 4 & 3 & 4 & 3 \\
\hline & 3 & 2 & 4 & 3 & 3 & 3 \\
\hline \multirow{4}{*}{$\begin{array}{l}\text { (Eight patients } \\
\text { each) }\end{array}$} & 3 & 3 & 4 & 4 & 4 & 3 \\
\hline & 2 & 2 & 4 & 3 & 3 & 3 \\
\hline & 2 & 2 & 4 & 4 & 3 & 3 \\
\hline & 2 & 1 & 3 & 2 & 3 & 1 \\
\hline \multirow{7}{*}{$\begin{array}{l}\text { WEEK } 8 \\
\text { Post denture } \\
\text { insertion } \\
\text { (Eight patients } \\
\text { each) }\end{array}$} & 2 & 2 & 4 & 1 & 2 & 2 \\
\hline & 2 & 1 & 3 & 2 & 2 & 1 \\
\hline & 3 & 3 & 4 & 1 & 3 & 1 \\
\hline & 2 & 1 & 3 & 1 & 2 & 1 \\
\hline & 3 & 2 & 4 & 1 & 2 & 2 \\
\hline & 2 & 2 & 3 & 1 & 2 & 1 \\
\hline & 2 & 1 & 1 & 1 & 2 & 1 \\
\hline $\begin{array}{l}\text { TOTAL=24 } \\
\text { Patients }\end{array}$ & & & & & & \\
\hline
\end{tabular}

*S1- Rugae Duplicated by wax pattern from mucocompressive impression in shallow palate- Mc

*S2-Rugae Duplicated by wax pattern from mucostatic impression in shallow palate - Ms

*M1- Rugae Duplicated by wax pattern from mucocompressive impression in Medium palate- Mc

*M2-Rugae Duplicated by wax pattern from mucostatic impression in shallow Medium - Ms

*D1- Rugae Duplicated by wax pattern from mucocompressive impression in Deep palate- Mc

*D2-Rugae Duplicated by wax pattern from mucostatic impression in Deep palate - Ms

\section{Statistical analysis}

The intergroup analysis of two maxillary dentures using Mucocompressive and Mucostatic technique for twenty four patients over a period of eight weeks of different palatal vaults using Mann-Whitney $\mathrm{U}$ test is as follows:

Table 2: For Shallow Palatal Vault

\begin{tabular}{llllll}
\hline Variable & $\begin{array}{l}\text { Tech- } \\
\text { nique }\end{array}$ & $\begin{array}{l}\text { Mea } \\
\mathrm{n}\end{array}$ & $\begin{array}{l}\text { Standard Devia- } \\
\text { tion }\end{array}$ & $\begin{array}{l}\text { Medi- } \\
\text { an }\end{array}$ & p-value \\
\hline $1^{\text {st }}$ Week & Mc & 4.13 & 0.64 & 4.0 & \\
& Ms & 3.38 & 0.52 & 3.0 & $\begin{array}{l}0.0279 \\
*\end{array}$ \\
$2^{\text {nd }}$ & & & & & \\
Week & Mc & 2.88 & 0.64 & 3.0 & \\
& & & & & 0.0451 \\
$8^{\text {th }}$ Week & Mc & 2.25 & 0.46 & 2.0 & $*$ \\
& Ms & 2.25 & 0.46 & 2.0 & \\
& & 1.63 & 0.74 & 1.5 & 0.0608 \\
\hline
\end{tabular}

Table 3: For Medium Palatal Vault

\begin{tabular}{clllll}
\hline Variable & Technique & Mean & $\begin{array}{l}\text { Standard } \\
\text { Deviation }\end{array}$ & Median & p-value \\
\hline $1^{\text {st }}$ Week & Mc & 4.4 & 0.5 & 4.0 & \\
& Ms & 4.3 & 0.7 & 4.0 & 0.7651 \\
$2^{\text {nd }}$ Week & Mc & 3.8 & 0.5 & 4.0 & \\
& Ms & 3.4 & 0.5 & 3.0 & 0.1432 \\
$8^{\text {th }}$ Week & Mc & 3.1 & 1.0 & 3.0 & \\
& Ms & 1.3 & 0.5 & 1.0 & $0.0027^{*}$ \\
\hline
\end{tabular}

Table 4: For Deep Palatal Vault

\begin{tabular}{|c|c|c|c|c|c|}
\hline Variable & $\begin{array}{l}\text { Tech- } \\
\text { nique }\end{array}$ & $\begin{array}{l}\text { Mea } \\
\mathrm{n}\end{array}$ & $\begin{array}{l}\text { Standard Devia- } \\
\text { tion }\end{array}$ & $\begin{array}{l}\text { Medi- } \\
\text { an }\end{array}$ & p-value \\
\hline \multirow[t]{2}{*}{$1^{\text {st }}$ Week } & $\mathrm{Mc}$ & 4.38 & 0.52 & 4.0 & \multirow{3}{*}{0.1128} \\
\hline & Ms & 3.88 & 0.64 & 4.0 & \\
\hline \multirow[t]{2}{*}{$\begin{array}{l}2^{\text {nd }} \\
\text { Week }\end{array}$} & Mc & 3.38 & 0.52 & 3.0 & \\
\hline & Ms & 2.75 & 0.46 & 3.0 & $\begin{array}{l}0.0291 \\
*\end{array}$ \\
\hline \multirow[t]{2}{*}{$8^{\text {th }}$ Week } & $\mathrm{Mc}$ & 2.25 & 0.46 & 2.0 & \multirow[b]{2}{*}{$\begin{array}{l}0.0026 \\
*\end{array}$} \\
\hline & Ms & 1.25 & 0.46 & 1.0 & \\
\hline
\end{tabular}

$* \mathrm{p}<0.05$

The mean value of scores tabulated for $1^{\text {st }}$ week in three palatal vaults was in the range between 3.8 to 4.4indicating that irrespective of depth of palatal vault speech could be understood with difficulty and concentration only by the family members or by a sympathetic listener. $p$-values $(p<0.05)$ were highly significant at $8^{\text {th }}$ week when mucostatic impression was used for rugae duplication particularly in medium and deep palatal vaults and $2^{\text {nd }}$ week for shallow palatal vault. The intra -group analysis using Wilcoxon-matched pair test was used to compare the score obtained in first week to eight week in the same group so as to evaluate the improvement in speech.it was observed that $\mathrm{p}$ value was significant in speech recorded from denture wherein, rugae was duplicated using mucostatic impression irrespective of palatal depth.(Table5,6\&7).

Table 5: Comparison of Speech Recorded after $1^{\text {st }}$ and $8^{\text {th }}$ Weekpost Denture Insertion with Respect to Shallow Palatal Vault of Two Maxillary Dentures by Wilcoxon Matched Pairs Test.

\begin{tabular}{lllll}
\hline Technique & & Mean & Standard Deviation & p-value \\
\hline Mc & 1 Week & 4.1 & 0.6 & \\
& 8 Weeks & 2.3 & 0.5 & 0.0217 \\
Ms & 1 Week & 3.4 & 0.5 & \\
& 8 Weeks & 1.6 & 0.7 & 0.0165 * $^{*}$ \\
\hline
\end{tabular}

$* \mathrm{p}<0.05$.

Table 6: Comparison of Speech Recorded after $1^{\text {st }}$ and $8^{\text {th }}$ Week Post Denture Insertion with Respect to Medium Palatal Vault of Two Maxillary Dentures by Wilcoxon Matched Pairs Test.

\begin{tabular}{lllll}
\hline Technique & & Mean & Standard Deviation & p-value \\
\hline Mc & 1 Week & 4.4 & 0.5 & \\
& 8 Weeks & 3.1 & 1.0 & $0.0242 *$ \\
Ms & 1 Week & 4.3 & 0.7 & \\
& 8 Weeks & 1.3 & 0.5 & $0.0125^{*}$ \\
\hline *p<0.05 & & & &
\end{tabular}


Table 7: Comparison of Speech Recorded after $1^{\text {st }}$ and $8^{\text {th }}$ Week Post Denture Insertion with Respect to Deep Palatal Vault of Two Maxillary Dentures by Wilcoxon Matched Pairs Test.

\begin{tabular}{lllll}
\hline Technique & & Mean & Standard Deviation. & p-value \\
\hline Mc & 1 Week & 4.4 & 0.5 & \\
& 8 Weeks & 2.3 & 0.5 & $0.0257^{*}$ \\
Ms & 1 Week & 3.9 & 0.6 & \\
& 8 Weeks & 1.3 & 0.5 & $0.0117^{*}$ \\
\hline * $<<0.05$ & & & &
\end{tabular}

\section{Discussion}

Definite pressure impressions record the tissues in compressed form; they grip the tissues with sufficient pressure once the impressions are made tissues rebound (Kazanjeet al. 2008). On the other hand, the other hand Minimal pressure technique or pressureless impressions are one made with the least possible displacement of soft tissues covering the residual alveolar ridge; they record the tissues without distortion with every detail of the mucosa. Tongue is a principal articulator for speech, and learning its position for given sound is the key to speech learning. Its positioning in contact with hard palate \& soft palate causes pronunciation of many vowels and consonants (phonemes). A few have recognized the importance of palatal contour Snow (1899) restored the anterior lingual area to restore phonetics, to promote pronunciation of $/ \mathrm{s} /$ and $/ \mathrm{sh} /$ sound. Prendergast (1935) pointed out proper thickening of the lingual alveolar area was important for proper speech. In the present study attempt was made to establish or find out correlation between palatal vaults and speech enhancement when rugae were duplicated but as seen in Figure 9,10,\&11 tongue and palatal contact for pronunciation of speech did not depend upon the depth of the palatal vault moreover ,dentures wherein rugae were duplicated using mucostatic principle resulted in faster improvement in speech, mainly because tissues were not recorded in compressed state. With decrease in mean values of scores according to speech rating scale from a range of 4-3 in $1^{\text {st }}$ week to 2 1 in eight week for mucostatic technique, scores for mucocompressive technique range from $4-5$ in $1^{\text {st }}$ week to $2-3$ in eight weeks indicates that mucostatic principle holds better results than mucocompressive for rugae duplication . Palmer(1979 stated that structural changes in dentures like an non-anatomic papilla placed on oral side somewhat posterior to papilla could serve both a source of turbulence and for tactile locating purposes, this tiny papilla tried out first in wax is conical, about 3-4 $\mathrm{mm}$ in diameter at its base, but perhaps only 1-3 $\mathrm{mm}$ in height, no polishing of changed area should take place, tongue finds it easier to identify the somewhat irregular and rough region than slippery and smooth area(Palmer JM 1979). Artificial duplication can be done using corrugated metal plates, Plastic palate forms, free hand wax carving of anatomical palate forms etc. These artificial rugae may cause interference with speech if they are made too prominent (Meeru Paul 2010). The use of ribbed features, when made from a significantly stiffer material and designed to mimic palatal rugae, offer an acceptable method of providing significant improvement in speech as well as rigidity to maxillary denture(White JA etal. 2011).Optimal phonetics can be best achieved by obtaining a proper occlusal vertical dimension (OVD) and occlusal plane, correctly positioning the anterior and posterior teeth according to the esthetic and functional requirements of the patient, and adequately contouring the palatal surface. Once teeth are correctly positioned at the correct OVD and on a proper occlusal plane, the waxed palatal contour of a maxillary complete denture should be evaluated for speech intelligibility because incorrect tooth positions may also cause sibilant distortions. The physiologic /s/ sound is formed by adaptation of the lateral margins of the tongue to the palatal alveolar process of the posterior maxillae, channeling a stream of air through the medial groove on the dorsum of the tongue behind the maxillary central incisors(Hansen CA et al. 1987)(Farley DW et al. 1998).Kong HJ et al (2008) described a technique for customizing the palatal contour of a maxillary complete denture with auto polymerizing acrylic resin to improve the intelligibility of speech using a palatogram simple and useful diagnostic tool for phonetic evaluation of a maxillary complete denture patient, and functions by representing a static record of contact area between the palate and the tongue upon pronunciation of sounds (Kong $\mathrm{HJ}$ et al. 2008). The authors in this study, recorded the dynamic contact of the tongue using a tissue conditioning material in undercontoured anterior palatal surface of the denture by asking the patient to read ten stimulus sentences stressing on linguo palatal words, later the customized contour that was formed was incorporated in the definite prosthesis using autopolymersisng acrylic resin. Evaluation or the intelligibility of/s/ and /sh/ sounds with the denture was carried out. If a whistle persists, the airstream was further impeded by carving ridges (rugae) with a \#6 round bur to enhance air turbulence and tactile sensitivity. If a central lisp persisted, reduction of excessive anterior contour and polishing the prostheses, or cutting a V-shaped groove in the center and parallel to the course of the airstream was carried out. In the present study, contour of the existing rugae was adequately recorded in a mucostatic impression rather than mucocompressive impression material thereby avoiding under contouring or over contouring. By altering the palatal contour of the maxillary denture for a patient who has sibilant distortions, improved intelligibility of the sounds and/or a reduced period of adaptation can be achieved (Kong HJ et al. 2008).

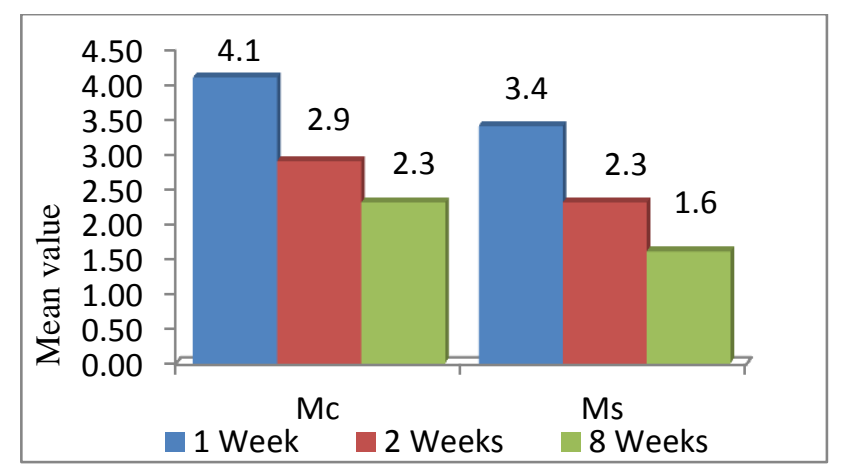

Fig. 8: Comparison of 1 Week, 2 Weeks and 8 Weeks with Respect to Shallow Palatal Vault in Mc and Ms Techniques.

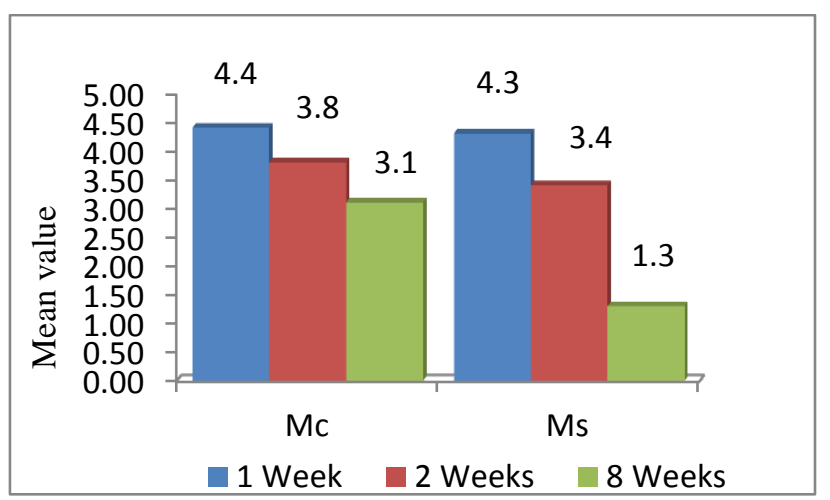

Fig. 9: Comparison of 1 Week, 2 Weeks and 8 Weekswith Respect to Medium Palatal Vault in Mc and Ms Techniques.

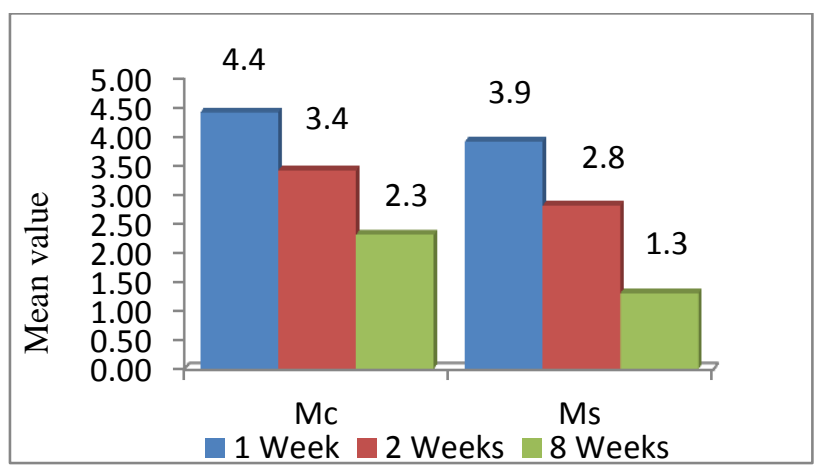

Fig. 10: Comparison of 1 Week, 2 Weeks and 8 Weeks with Respect to Deep Palatal Vault in Mc and Ms Techniques. 


\section{Conclusion}

Within the confines of this study, phonetics is better served by keeping the posterior ridge area in the denture as thin as possible and confining the palatal contour in anterior region. Irrespective of depth of palatal vault, mucostatic impression material is more appropriate as a material of choice for rugae duplication and wax pattern fabrication as it least compresses the rugae during impression making, restores phonetics in complete denture within shorter duration of time.

\section{References}

[1] Allen,L.R (1958) Improved Phonetics in Denture construction.J Prosthet Dentistry 8,753-736. http://dx.doi.org/10.1016/00223913(58)90095-7.

[2] Martone, A.L (1963) Clinical applications of concepts of Functional Anatomy and Speech Science to complete denture prosthodontics.J Prosthet Dentistry 13, 4-33. http://dx.doi.org/10.1016/00223913(63)90194-X.

[3] Tanaka H (1973) Speech patterns of edentulous patients and morphology of palate in relation to phonectics.J Prosthet Dentistry 29, 16-28. http://dx.doi.org/10.1016/0022-3913(73)90135-2.

[4] Farley D, Jones D.J (1998) Palatogram assessment of Maxillary Complete denture.Journal of Prosthodontics 7(2), 84-90. http://dx.doi.org/10.1111/j.1532-849X.1998.tb00185.x.

[5] Kazanje MN, INoori SY (2008) Measurement of Palatal Depth for Completely Edentulous Patient.Al-Rafidain Dentistry Journal 8(1), 23-25.

[6] Zarb GA, Bolender CL, Hickey JC (1985) Prosthodontic Treatment for Edentulous Patients, The CV Mosby Company.

[7] Sharry JJ (1974) Complete Denture Prosthodontics, McGraw-Hill.

[8] Palmer JM (1979) Structural changes for speech Enhancement in complete upper denture fabrication.J Prosthet Dentistry 41,507-10. http://dx.doi.org/10.1016/0022-3913(79)90081-7.

[9] Meenu Merry C Paul. A simple technique of fabricating customized palatal rugae contours in complete dentures for enhancing phonetics KDJ April 2010;33(2) :110

[10]White JA, Blood IP, Jagger DC.Improving mechanical properties of maxillary complete dentures through a bioinspirsed engineering design. Int J Prosthodont Nov-Dec 2011; 24(6):589-98.

[11]Runte C, Lawerino M, Dirksen D, BollmannF, Lamprecht-Dinnesen A, Seifert E. The influenceof maxillary central incisor position in complete dentures on /s/ sound production.J Prosthet Dent 2001; 85:48595. http://dx.doi.org/10.1067/mpr.2001.114448.

[12]Kong HJ,Hansen CA .Customizing palatal contours of a denture to improve speech Intelligibility.J Prosthet Dent 2008;99(3):243-48. http://dx.doi.org/10.1016/S0022-3913(08)60049-9.

[13]Farley DW, Jones JD, Cronin RJ. Palatogram assessment of maxillary complete dentures.J Prosthodont 1998; 7:84-90. http://dx.doi.org/10.1111/j.1532-849X.1998.tb00185.x.

[14] Hansen CA, Singer MT. Correction of defective sibilant phonation created by a complete maxillary artificial denture. GenDent 1987; 35:357-60. 